a straightforward and non-technical way the foundations for the practical instruction which follows. Next come the principles of therapy and management, with sensible and sometimes original forms of treatment, and then follows a discussion of the various syndromes, all treated separately and comprehensively-pathogenesis, symptomatology, differential diagnosis, treatment, and so on. Each chapter has a useful list of references, and the text is enlivened throughout by humorous illustrations. This is not the place to discuss the ethics of humour in medical texts, suffice it to say here that these drawings are not only in excellent taste, but would prove extremely useful if reproduced for the patients, and have been, in fact, included for this purpose.

This work is more than a manual, however useful it may prove in medical practice, for the author makes clear the dangers in extreme attitudes -not only the cautious but the over-enthusiastic. His explanation of the non-psychogenic functional disorders has an important place in psychosomatic literature, and his theories, though simple, make sense of much that appears complicated when stated in more wordy prose. Good reading for student and experienced clinician alike, this book is specially recommended to those just entering general practice.

\section{SKIN GRAFTING}

By James Barrett Brown, M.D. and Frank McDowell, M.D. Third Edition. Pp. xv + 4I I, with 328 illustrations, and six colour plates. London. Pitman Medical Publishing Co. Ltd. 1958. £5 5s.

This book, the third edition, is an expanded work based on 'Skin Grafting of Burns,' by the same authors, published in 1943, and an intermediate volume, 'Skin Grafting,' of 1949 . The enlargement from some 200 pages in the first edition, and 332 in the second, is brought about by several means.

The subject of burns is dealt with in all its aspects, and this section has been expanded in the light of modern developments. Other chapters have been enlarged, and fresh ones added, notably those concerned with trauma in civilian life, and radiation burns.

The student of Plastic Surgery will find this a useful and readable book, which does not burden him with too much operative detail. In one relatively short section pedicle flaps of all kinds are explained clearly, together with their uses, and their preparation. The use of local flaps, as opposed to distant tube pedicles, is rightly emphasized, and the authors constantly point out the desirability of completing a surgical programme in the minimum number of operations.

There is much of a repetitive nature, especially in the burns section, and many of the photographs and illustrations, some of them rather poor, do tend to split up the text unnecessarily, and cause the readêr constantly to search among pages already read for diagrams quoted in the pages following.

The use of homografts in the severely burned patient is explained, and helpful suggestions are made regarding the organization of post morte skin banks. This section, together with that diss cussing radiation burns, and like injuries, is a most interesting and valuable addition, which , coute become of great importance in a national emergenc.

In any subsequent edition improvements in the presentation of this work should produce a firsts class book out of what is, at the moment, a good one.

\section{SURGERY OF THE SYMPATHETIC NERVOUS SYSTEM}

By Professor Sir James Paterson Ross, K.C.V.O

LL.D., M.S., F.R.C.S., F.R.A.C.S., F.A.C.S్ Third Edition. Pp. xii + 170, illustrated London: Baillère, Tindall \& Cox. 1958. 35\$

Twenty years ago Sir James Paterson Ros published the last edition of his book on the Surger of the Sympathetic Nervous System. A new edition after this lapse of time is most welcome This is a short book written by a master who, as $\frac{10}{3}$ result of long experience, knows what is important and what can be omitted. Surgeons will find that this is a monograph of great practical valug During the past decade sympathectomy has $\overline{6}$ sit much of its appeal, largely because it has beo performed too frequently and also on many un suitable patients. Sir James Paterson Ross corrects this impression and tells the surgeon the real valuog of this most useful operation.

\section{FUNGUS DISEASES AND THEIR TREATMENT}

Edited by R. W. RIDDELL, M.D.(Lond.), F.R.C.PS (Edin.), and G. T. STEWART, B.Sc., M.D.(Glas. D.T.M. \& H. Pp. xvii $+256+$ index, illus trated. London: Butterworth \& Co. Ltd. 1958 45s.

Mycology is a neglected subject in this countryo We largely depend on American authors for ou textbooks and, while some of these are excellent and are based on wide experience, they tend $t \bar{\theta}$ leave a false impression of the frequency in thit country of the conditions described.

This book will help to restore a balanced poin of view at a time when the fungous diseases are growing in importance. It is not a true textbool nor a review; it is described by the publishers as work of reference but is, in fact, an edited serie of papers given in a symposium held at th Brompton Hospital in July 1957 . There are $2 \dot{2}$ articles on the pathology and epidemiology of the diseases and, in the second part, nine on treatment 
These are presented by responsible workers from this country and from abroad.

It is a pleasure to record that the photographs are excellent and few have lost anything of their original quality. The photo-micrographs not only show what is claimed but they are technically as good as anything available anywhere for teaching purposes. Since the war it is rare for a British production to be better in this respect than its American rivals.

This book can be read with advantage by anyone who feels that his knowledge of this group of diseases is inadequate or may be out of date. It will give him a clear picture of the present state of knowledge and honestly draw attention to the gaps yet to be filled.

W.H.H.

\section{ABDOMINAL OPERATIONS BY THE VAGINAL ROUTE}

By Paul M. Werner, M.D. and Julius Sederl, M.B. (Translated from the German by L. M. Szamec, M.D.) Pp. vi + I65, fully illustrated. London: Pitman Medical Publishing Co. Ltd. 1958. $65 \mathrm{~s}$.

This is an American translation of a book by two Viennese gynaecologists. It describes vaginal hysterectomy, including the removal of the large fibroid uterus by morcellation, vaginal removal of ovarian tumours, the vaginal route for dealing with ectopic pregnancy, tubal sterilization by the vaginal route and the interposition operation.

On the continent of Europe, especially in Austria and Italy and in certain States of America such as California, vaginal gynaecological surgery has reached an extremely high standard: probably unequalled any where in this country. This book is worth consulting as an object lesson how to carry out vaginal procedures in those few patients in this country who refuse to have an abdominal scar.

Even the authors of this book, enthusiastic as they are, do not recommend the vaginal route for ectopic pregnancy but they do show how such a condition can be dealt with vaginally.

The most remarkable pages in the book, as far as your reviewer is concerned, are those showing the method perfected by Logothetopulos.

Any bleeding in the pelvis can for certain be stopped by the insertion of a massive tampon. The method is ingenious in the extreme and probably effective too. Because of it, the nightmare of the lipped pedicle in vaginal surgery has disappeared. (Your reviewer tried it out on a case of a combined synchronous abdominoperineal anterior extenterafion in a very old lady and found it roo per cent. effective.)

This is a book that every gynaecological surgeon ractising really major surgery should own or at least ead. It is not a book for undergraduates, nor eally for the post-graduate student.

It is very well produced.

\section{TOPICJ IN PSY CHIATRY}

Edited by T. Ferguson Rodger, R. M. MowBRAY and J. R. Roy. Pp. $x+265$. London: Cassell \& Co. Ltd. I 958 . 20s.

In this volume some two dozen contributors record the Proceedings of a Specialist Conference in Psychiatry held in Glasgow in October 1957. The added impetus which psychiatric research has received in the last year or two makes this a singularly opportune time to record facets of progress in this specialty by a well-organized and enthusiastic group of clinical scientists.

There are five sections, each with its own editorial introduction, covering schizophrenia, psychosomatic medicine, tranquillizing drugs, mental deficiency, and biochemical genetics. The papers which make up these sections do not pretend to be comprehensive or exhaustive, but each in its modest way makes a definite contribution to the subject as a whole, and possesses an inter-relevance wisely pointed out in the editorial.

The chapters vary considerably in length and quality, but the careful editing prevents this from appearing as an uneven text. Completely free from theoretical bias and with no adherence to any one school of thought, this book provides a very good vignette of mid-century psychiatry, in which psychoanalysis rubs shoulders with psychopharmacology, and explanations range from the verballyo descriptive to the analytically statistic.

As well as pointing out the dominant problemse facing psychiatry today, this book carries an optimism shared by most of its contributors for the future of that backwater of medicine-mental deficiency. It is very satisfying to see so much interest in oligophrenia not only maintained but directed in a positive manner towards solutions of what are often thought to be insoluble problems.

This is an inexpensive volume which gives an informative and very readable account of contemporary psychiatric research, pointing out most clearly, not only the changing face of psychiatry, but the way in which so many disparate viewpoints can profitably converge.

\section{MUIR'S TEXTBOOK OF PATHOLOGY}

Revised by D. F. CAppell, C.B.E., M.D., F.R.F.P.S., M.R.C.P., F.R.S.(Edin.). Seventh Edition. Pp. $x x+1201$, with 733 illustrations. London: Edward Arnold Ltd. 1958.70 .

The ever-increasing volume of medical knowledge makes the production of a single-author textbook seemingly impossible, yet Professor Cappell, in this seventh edition of 'Muir,' has succeeded in writing a really up-to-date account of pathology.

A particularly pleasing feature is the way in which the functional aspects of disease are discussed as well as the morphological, for it was this slavish devotion to purely morbid anatomical 